\title{
Is there theoretical evidence for mutual influence between halogen and pnicogen-hydride bonds? An $a b$ initio study
}

\author{
ELAHE PARVINI $^{\mathrm{a}}$, MORTEZA VATANPARAST ${ }^{\mathrm{a}, *}$, ESMAIL VESSALLY $^{\mathrm{b}}$ and \\ ALI BAHADORI ${ }^{\mathrm{c}}$ \\ ${ }^{a}$ Young Researchers and Elite Club, Tabriz Branch, Islamic Azad University, Tabriz, Iran \\ ${ }^{b}$ Department of Chemistry, Payame Noor University, Tehran, Iran \\ ${ }^{c}$ Department of Chemistry, University of Applied Science and Technology, Tehran, Iran \\ e-mail: M.Vatanparast@tabrizu.ac.ir; MVatanparast@yahoo.com
}

MS received 12 July 2016; revised 13 September 2016; accepted 19 October 2016

\begin{abstract}
Ab initio MP2/6-311++G(d,p) level calculations have been carried out to investigate the interplay between the halogen and pnicogen-hydride bonds in $\mathrm{NCX} \cdots \mathrm{OPH}_{3} \cdots \mathrm{HMgY}$ complexes $(\mathrm{X}=\mathrm{F}, \mathrm{Cl}, \mathrm{Br} ; \mathrm{Y}=$ $\mathrm{F}, \mathrm{Cl}, \mathrm{Br}, \mathrm{H})$. The results indicated that the cooperative effects are obvious in the target complexes. These effects were considered in detail in terms of electrostatic potential, energetic, geometric, charge-transfer and electron density properties of the complexes. The values of cooperative energy $\left(\mathrm{E}_{\mathrm{coop}}\right)$ were ranging from -0.41 to $-0.60 \mathrm{~kJ} / \mathrm{mol},-1.02$ to $-1.57 \mathrm{~kJ} / \mathrm{mol}$ and -1.50 to $-2.28 \mathrm{~kJ} / \mathrm{mol}$ for $\mathrm{X}=\mathrm{F}, \mathrm{Cl}$ and $\mathrm{Br}$, respectively. Based on many-body analysis, two and three-body terms of interaction energies have a positive contribution to the total interaction energy. It was found that the amount of charge transfer in the triads is higher than that in the corresponding dyads. AIM analyses showed that the halogen and pnicogen-hydride bonds in the triads are amplified with respect to the dyads.
\end{abstract}

Keywords. Cooperativity; Pnicogen-hydride bond; halogen bond; Ab initio study.

\section{Introduction}

The importance of noncovalent interactions is due to their widespread applications in many fields such as, physical, chemical, and biological systems. ${ }^{1}$ Although the hydrogen bond is probably the most important intermolecular interaction, ${ }^{2-5}$ interest has grown for other types of intermolecular interactions, such as halogen bond $^{6-9}$ and lithium bond. ${ }^{10}$ A halogen bond is a shortrange $\mathrm{R}-\mathrm{X} \cdots \mathrm{B}$ interaction between a halogen atom $(\mathrm{X})$ in one molecule $(\mathrm{R}-\mathrm{X})$ and a negative site in a donor of electron density B. ${ }^{11}$ The term " $\sigma$-hole" is a region of positive electrostatic potential on the outer surface of $\mathrm{X}$ along the bond axis that explains the stability of the X-bond. ${ }^{12}$ The main origin of halogen bonding interaction is the electrostatic attraction between the $\sigma$-hole of halogen atom and the negative Lewis base. ${ }^{13}$ With increasing size of the halogen, $\mathrm{Cl}<\mathrm{Br}<\mathrm{I}, \sigma$-hole becomes larger and more positive. However, $\sigma$-hole interactions have been perused extensively for halogen bonding (Group VII), and their incidence for Groups IV-VI is increasingly being identified. ${ }^{14}$

In recent years, pnicogen bond as a new type of intermolecular interaction has attracted much attention since

\footnotetext{
*For correspondence
}

Hey-Hawking et al., ${ }^{15}$ revealed in 2011 that it may act as a molecular linker in crystal materials. ${ }^{16}$ The pnicogen bond is a noncovalent interaction between a pnicogen atom in one molecule and an electron-rich site in another molecule. As mentioned in the previous paragraph, the formation of pnicogen bond can be described with the help of the $\sigma$-hole concept. ${ }^{17-23} \mathrm{Li}$ et al., predicted in 2012 that a pnicogen-hydride bond can exist in $\mathrm{FH}_{2} \mathrm{P} \cdots \mathrm{HM}$ and $\mathrm{FH} 2 \mathrm{As} \cdots \mathrm{HM}(\mathrm{M}=\mathrm{ZnH}, \mathrm{BeH}$, $\mathrm{MgH}, \mathrm{Li}$, and $\mathrm{Na}$ ) complexes. ${ }^{24}$ In this different type of pnicogen bond, a metal hydride acts as the electron donor to form the pnicogen-hydride bond.

When the noncovalent interactions act simultaneously, reciprocally and mutually to enhance the strength, they are said to be acting cooperatively. The cooperativity, like the competition behavior, is another significant type of intermolecular interaction. ${ }^{25-28}$ Cooperativity effect plays an essential role in specifying the behavior in some biochemical and chemical systems. ${ }^{29}$ The interplay between pnicogen-bond and halogen-bond in $\mathrm{XCl} \cdots \mathrm{FH}_{2} \mathrm{P} \cdots \mathrm{NH}_{3}(\mathrm{X}=\mathrm{F}, \mathrm{OH}, \mathrm{CN}, \mathrm{NC}$, and $\mathrm{FCC})$ complex has recently been investigated by $\mathrm{Li}$ et al $^{30}$ Their results indicate that both types of interaction enhance each other. The cooperative effects between $\mathrm{F}-$ $\mathrm{H} \cdots \mathrm{F}$ hydrogen bond and $\mathrm{P} \cdots \mathrm{N}$ pnicogen bond were studied by by Alkorta et al. ${ }^{31}$ The cooperativity between 
pnicogen bond and dihydrogen bond interactions in $\mathrm{HMH} \cdots \mathrm{HCN} \cdots \mathrm{PH}_{2} \mathrm{X}(\mathrm{M}=\mathrm{Be}, \mathrm{Mg}, \mathrm{Zn} ; \mathrm{X}=\mathrm{H}, \mathrm{F}$, $\mathrm{Cl})$ complexes was also studied by Esrafili et al. ${ }^{32}$

To the best of our knowledge, the interplay between the halogen and pnicogen-hydride bonds has not yet been investigated. In this regards, we designed some simple structures including halogen and pnicogenhydride bonds. We carried out a theoretical study on

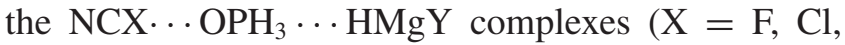
$\mathrm{Br} ; \mathrm{Y}=\mathrm{F}, \mathrm{Cl}, \mathrm{Br}, \mathrm{H})$ with the aim of investigating the mutual influence between halogen and pnicogenhydride bonds. The properties and nature of interaction have also been understood with atoms in molecules (AIM), ${ }^{33}$ natural bond orbital (NBO). ${ }^{34}$ and molecular electrostatic potential (MEP). ${ }^{35}$

\section{Computational methods}

All geometry optimizations were performed at MP2/ $6-311++\mathrm{G}(\mathrm{d}, \mathrm{p})$ level of theory using Gaussian 03 program. ${ }^{36}$ Recently, it has been shown that MP2 method is able to accurately predict the interaction energies of the halogen-hydride interactions. ${ }^{37}$ The vibrational frequency calculations were carried out at the same level to guarantee that the structures obtained corresponded to local minima on the potential energy surface. All the interaction energies were calculated at the same level as the difference of the total energy of the complexes and the sum of the isolated monomers, without any geometrical flexibility. To determine the corrected interaction energy, the basis set superposition error (BSSE) correction was also calculated according to the counterpoise (CP) method proposed by Boys and Bernardi. ${ }^{38}$

Molecular electrostatic potentials were computed with Wave Function Analysis-Surface Analysis Suite (WFA-SAS) developed by Politzer et al. ${ }^{39}$ The AIM analysis was performed by means of the AIM2000 program. ${ }^{40}$ using the MP2 $/ 6-311++\mathrm{G}(\mathrm{d}, \mathrm{p})$ wavefunction. The NBO calculations were performed at the MP2/6-311++G(d,p) level by means of the NBO 3.1 program. $^{41}$

\section{Results and Discussion}

\subsection{Molecular electrostatic potential}

Molecular electrostatic potential (MEP) is a well-established tool for studying the nature of intermolecular interactions and interpreting and predicting noncovalent interactions. One of the real physical properties is electrostatic potential. It is experimentally determined by diffraction methods, and also with computational methods. Potential is one of the basic features of molecules that can determine many of its properties. ${ }^{42-45}$ The three dimensional MEP maps on the 0.001 electron/Bohr ${ }^{3}$ electron density isosurfaces of the monomers $\mathrm{OPH}_{3}$, $\mathrm{NCBr}$ and $\mathrm{HMgBr}$ and their complexes are depicted in Figure 1. As expected, there is a positive region of MEP outside the phosphorus atom along the extension of $\mathrm{O}-\mathrm{P}$ bond and is surrounded by negative electrostatic

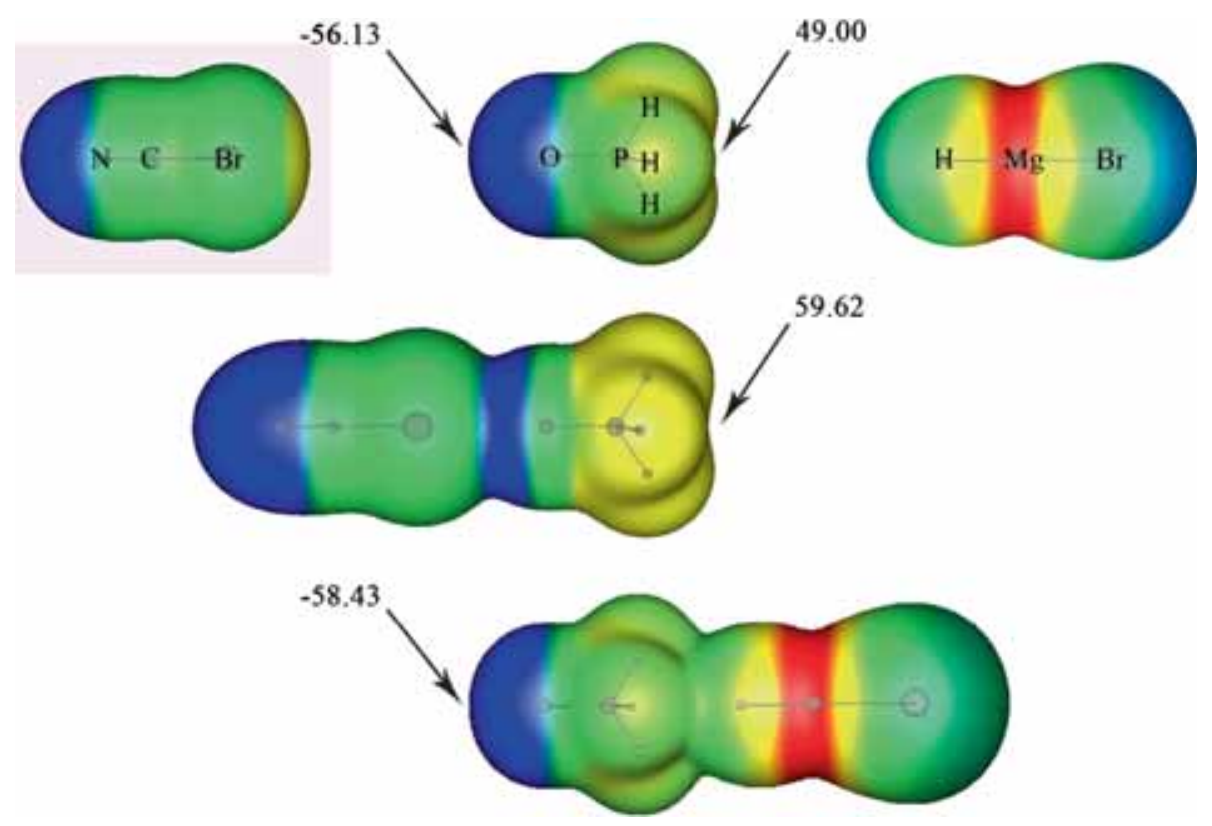

Figure 1. Electrostatic potential maps on the 0.001 (electron/Bohr ${ }^{3}$ ) electron density isosurfaces of isolated $\mathrm{NCBr}, \mathrm{OPH}_{3}$, and $\mathrm{HMgBr}$ and their binary complexes. Color ranges, in kcal mol ${ }^{-1}$ : red $>60>$ yellow $>20>$ green $>-15>$ blue. 
potential, which corresponds to the $\sigma$-hole. Except for the positive MEP region outside the phosphorus atom, there is also a negative potential $\mathrm{V}_{\mathrm{S} \text {, min }}$ associated with the oxygen atom along the extension of $\mathrm{O}-\mathrm{P}$ bond.

The most positive $\left(\mathrm{V}_{\mathrm{S}, \max }\right)$ and most negative $\left(\mathrm{V}_{\mathrm{S}, \min }\right)$ electrostatic potentials are shown in Table 1. According to Table $1, \mathrm{~V}_{\mathrm{S} \text {, min }}$ value is $-56.13 \mathrm{kcal} / \mathrm{mol}$ for the $\mathrm{O}$ atom and $\mathrm{V}_{\mathrm{S}, \max }$ on the $\mathrm{P}$ atom is $49.00 \mathrm{kcal} / \mathrm{mol}$ in $\mathrm{OPH}_{3}$ monomer. For NCX, the positive region of MEP exists outside the $\mathrm{X}$ atom along the extension of $\mathrm{C}-\mathrm{X}$ bond. The $\mathrm{V}_{\mathrm{S}, \max }$ values, $33.03 \mathrm{kcal} / \mathrm{mol}, 41.34$ $\mathrm{kcal} / \mathrm{mol}, 48.93 \mathrm{kcal} / \mathrm{mol}$, increase in the order NCF $<\mathrm{NCCl}<\mathrm{NCBr}$. Therefore, $\mathrm{NCX} \ldots \mathrm{OPH}_{3}(\mathrm{X}=\mathrm{F}, \mathrm{Cl}$, $\mathrm{Br}$ ) dyads could be formed by the $\mathrm{X} \cdots \mathrm{O}$ halogen bond. As is clear from the Table 1, with the formation of the $\mathrm{X} \cdot \mathrm{O} \mathrm{O}$ halogen bond, the $\mathrm{V}_{\mathrm{S}, \max }$ values outside the $\mathrm{P}$ atom in $\mathrm{NCX} \cdots \mathrm{OPH}_{3}$ dyads become larger than that in $\mathrm{OPH}_{3}$ monomer, along the sequence of $\mathrm{Y}=\mathrm{F}, \mathrm{Cl}, \mathrm{Br}$. For $\mathrm{HMgY}(\mathrm{Y}=\mathrm{F}, \mathrm{Cl}, \mathrm{Br}, \mathrm{H})$, there is a negative region of MEP outside the hydrogen atom along the extension of $\mathrm{H}-\mathrm{Mg}$ bond, that become increasingly more negative in the order $\mathrm{HMgF}<\mathrm{HMgCl}<\mathrm{HMgBr}<\mathrm{HMgH}$. So, $\mathrm{OPH}_{3}$ and $\mathrm{HMgY}(\mathrm{Y}=\mathrm{F}, \mathrm{Cl}, \mathrm{Br}, \mathrm{H})$ can form $\mathrm{P} \cdots \mathrm{H}$ pnicogen-hydride bond, that is Group $\mathrm{V} \sigma$-hole interaction. When $\mathrm{OPH}_{3}$ forms the pnicogen-hydride bond with $\mathrm{HMgY}, \mathrm{V}_{\mathrm{S} \text {, min }}$ on the $\mathrm{O}$ atom becomes more negative, which demonstrates that the complexes are better electron donors than those of the corresponding monomers. From Table 1, with the formation of the $\mathrm{P} \cdot \mathrm{H}$ pnicogen-hydride bond, the $\mathrm{V}_{\mathrm{S} \text {,min }}$ values outside the oxygen atom in the bimolecular complexes $\mathrm{OPH}_{3} \cdots \mathrm{HMgY}$ become more negative than in $\mathrm{OPH}_{3}$ monomer, along the sequence of $\mathrm{Y}=\mathrm{F}, \mathrm{Cl}, \mathrm{Br}, \mathrm{H}$, which demonstrates that the complexes are stronger electron donors than the corresponding monomers. According to Table 1 , the $\mathrm{V}_{\mathrm{S} \text {, min }}$ values outside the oxygen atom in $\mathrm{OPH}_{3} \cdots \mathrm{HMgF}, \mathrm{OPH}_{3} \cdots \mathrm{HMgCl}$, $\mathrm{OPH}_{3} \cdots \mathrm{HMgBr}$ and $\mathrm{OPH}_{3} \cdots \mathrm{HMgH}$ are -58.32 , $-58.36,-58.43$ and $-60.72 \mathrm{kcal} / \mathrm{mol}$, respectively,

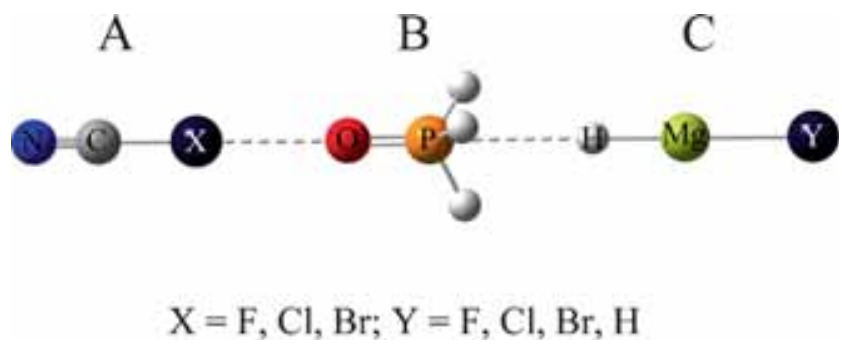

Figure 2. General structure of the $\mathrm{NCX} \cdots \mathrm{OPH}_{3} \cdots$ $\mathrm{HMgY}$ complex.

which are more negative than for the $\mathrm{OPH}_{3}$ monomer $\left(\mathrm{V}_{\mathrm{S}, \min }=-56.13 \mathrm{kcal} / \mathrm{mol}\right)$.

\subsection{Geometrics}

The geometrical changes can reflect the cooperative effect between the halogen bond and pnicogen-hydride bond. The optimized geometries of $\mathrm{NCX} \cdots \mathrm{OPH}_{3} \cdots$ $\mathrm{HMgY}(\mathrm{X}=\mathrm{F}, \mathrm{Cl}, \mathrm{Br}$; $\mathrm{Y}=\mathrm{F}, \mathrm{Cl}, \mathrm{Br}, \mathrm{H})$ are graphically shown in Figure 2. The oxygen atom in $\mathrm{OPH}_{3}$ is attracted to the $\sigma$-hole of NCX, at the same time the hydrogen atom in $\mathrm{HMgY}$ is attracted to the $\sigma$-hole of $\mathrm{OPH}_{3}$. The optimized equilibrium $\mathrm{C}-\mathrm{X} \cdots \mathrm{O}$ and $\mathrm{P} \cdot \mathrm{H}-\mathrm{Mg}$ contacts in the complexes are essentially linear.

The intermolecular distances for dyads and the distance difference between triads and dyads are listed in Table 2. The intermolecular distance in the halogen bonded dyads is smaller than that in the pnicogenhydride bonded dyads. The binding distances in the triads are shorter than those in the dyads, both the halogen bond and pnicogen-hydride distance. For example, the halogen bond distance of $\mathrm{NCF}$... $\mathrm{OPH}_{3}$ is $2.807 \AA$. With the formation of pnicogen-hydride bond in NCF... $\mathrm{OPH}_{3} \cdots \mathrm{HMgBr}$, the halogen bond distance becomes shorter to $2.795 \AA$. The pnicogen-hydride bond distance of $\mathrm{OPH}_{3} \cdots \mathrm{HMgBr}$ is $3.054 \AA$. With the formation of the halogen bond in $\mathrm{NCF} \cdots \mathrm{OPH}_{3} \cdots \mathrm{HMgBr}$,

Table 1. The most positive electrostatic potential, $\mathrm{V}_{\mathrm{S}, \max }(\mathrm{kcal} / \mathrm{mol})$, on the $\mathbf{P}$ and $\mathbf{X}$ atoms and the most negative electrostatic potential, $\mathrm{V}_{\mathrm{S}, \min }(\mathrm{kcal} / \mathrm{mol})$, on the $\mathbf{O}$ and $\mathbf{H}$ atoms in the monomers and dyad complexes.

\begin{tabular}{|c|c|c|c|c|c|}
\hline Monomer & $\mathrm{V}_{\mathrm{S}, \max }$ & $\mathrm{V}_{\mathrm{S}, \min }$ & Complex & $\mathrm{V}_{\mathrm{S}, \max }$ & $\mathrm{V}_{\mathrm{S}, \min }$ \\
\hline $\mathrm{OPH}_{3}$ & 49.00 & -56.13 & $\mathrm{OPH}_{3} \cdots \mathrm{HMgF}$ & - & -58.32 \\
\hline $\mathrm{HMgF}$ & - & -16.71 & $\mathrm{OPH}_{3} \cdots \mathrm{HMgCl}$ & - & -58.36 \\
\hline $\mathrm{HMgCl}$ & - & -16.54 & $\mathrm{OPH}_{3} \cdots \mathrm{HMgBr}$ & - & -58.43 \\
\hline $\mathrm{HMgBr}$ & - & -16.59 & $\mathrm{OPH}_{3} \cdots \mathrm{HMgH}$ & - & -60.72 \\
\hline $\mathbf{H M g H}$ & - & -24.85 & $\mathrm{NCF} \ldots \mathrm{OPH}_{3}$ & 52.56 & - \\
\hline $\mathrm{NCF}$ & 33.03 & - & $\mathrm{NCCl} \cdots \mathrm{OPH}_{3}$ & 56.46 & - \\
\hline NCCl & 41.34 & - & $\mathrm{NCBr} \cdots \mathrm{OPH}_{3}$ & 59.62 & - \\
\hline $\mathrm{NCBr}$ & 48.93 & - & & & \\
\hline
\end{tabular}


Table 2. Intermolecular distances $R(\AA)$ in the triads and their changes, $\Delta R(\AA)$, relative to the corresponding dyads.

\begin{tabular}{lcccc}
\hline Complex $(\mathrm{A} \cdots \mathrm{B} \cdots \mathrm{C})$ & $\mathrm{R}_{\mathrm{AB}}(\mathrm{T})$ & $\Delta \mathrm{R}_{\mathrm{AB}}$ & $\mathrm{R}_{\mathrm{BC}}(\mathrm{T})$ & $\Delta \mathrm{R}_{\mathrm{BC}}$ \\
\hline $\mathrm{NCF} \cdots \mathrm{OPH}_{3} \cdots \mathrm{HMgF}$ & 2.796 & -0.012 & 3.044 & -0.016 \\
$\mathrm{NCF} \cdots \mathrm{OPH}_{3} \cdots \mathrm{HMgCl}$ & 2.795 & -0.012 & 3.039 & -0.017 \\
$\mathrm{NCF} \cdots \mathrm{OPH}_{3} \cdots \mathrm{HMgBr}$ & 2.795 & -0.012 & 3.037 & -0.017 \\
$\mathrm{NCF} \cdots \mathrm{OPH}_{3} \cdots \mathrm{HMgH}$ & 2.791 & -0.016 & 2.995 & -0.021 \\
$\mathrm{NCCl} \cdots \mathrm{OPH}_{3} \cdots \mathrm{HMgF}$ & 2.798 & -0.015 & 3.008 & -0.052 \\
$\mathrm{NCCl} \cdots \mathrm{OPH}_{3} \cdots \mathrm{HMgCl}$ & 2.798 & -0.014 & 3.008 & -0.048 \\
$\mathrm{NCCl} \cdots \mathrm{OPH}_{3} \cdots \mathrm{HMgBr}$ & 2.798 & -0.014 & 3.005 & -0.049 \\
$\mathrm{NCCl} \cdots \mathrm{OPH}_{3} \cdots \mathrm{HMgH}$ & 2.789 & -0.024 & 2.960 & -0.056 \\
$\mathrm{NCBr} \cdots \mathrm{OPH}_{3} \cdots \mathrm{HMgF}$ & 2.773 & -0.019 & 2.992 & -0.069 \\
$\mathrm{NCBr} \cdots \mathrm{OPH}_{3} \cdots \mathrm{HMgCl}$ & 2.773 & -0.019 & 2.990 & -0.067 \\
$\mathrm{NCBr} \cdots \mathrm{OPH}_{3} \cdots \mathrm{HMgBr}$ & 2.773 & -0.019 & 2.988 & -0.066 \\
$\mathrm{NCBr} \cdots \mathrm{OPH}_{3} \cdots \mathrm{HMgH}$ & 2.763 & -0.029 & 2.941 & -0.076 \\
\hline
\end{tabular}

pnicogen-hydride bond distance becomes shorter to $3.037 \AA$. These results indicate that the halogen and pnicogen-hydride bond interactions become stronger from the dyad to the triad complexes. So, there is positive cooperativity between the halogen and pnicogenhydride bond interactions in triad complexes. For each triad, the shortening of the intermolecular distance in the pnicogen-hydride bond is more outstanding than that in the halogen bond. For example, it is $-0.066 \AA$ in the former and $-0.019 \AA$ in the latter for $\mathrm{NCBr}$. . $\mathrm{OPH}_{3} \cdots \mathrm{HMgBr}$ triad. This demonstrates that the effect of halogen bonds on pnicogen-hydride bonds is more than that of pnicogen-hydride bonds on halogen bonds.

\subsection{Interaction energies}

The interaction energy has been used generally in the study of the interplay between two types of noncovalent interactions. ${ }^{46}$ The interaction energy has been computed as the difference of the total energy of the complexes and the sum of the isolated monomers in their most stable formation. For example, the interaction energy in the triads is calculated with the formula of $E_{i}(A B C)=E_{A B C}-\left(E_{A}+E_{B}+E_{C}\right)$. To evaluate the interaction energies, basis set superposition error was corrected by the counterpoise method. Table 3 gives the interaction energy results for the $\mathrm{NCX} \cdots \mathrm{OPH}_{3} \cdots$ $\operatorname{HMgY}(\mathrm{X}=\mathrm{F}, \mathrm{Cl}, \mathrm{Br} ; \mathrm{Y}=\mathrm{F}, \mathrm{Cl}, \mathrm{Br}, \mathrm{H})$ complexes. The interaction energies of halogen bonds are -6.20 , -18.71 and $-25.16 \mathrm{~kJ} / \mathrm{mol}$ in $\mathrm{NCF} . . \mathrm{OPH}_{3}, \mathrm{NCCl} \ldots$ $\mathrm{OPH}_{3}$ and $\mathrm{NCBr} \cdots \mathrm{OPH}_{3}$ dyads, respectively. As can be seen in Table 3, the range of interaction energies of $\mathrm{OPH}_{3} \cdots \mathrm{HMgY}(\mathrm{Y}=\mathrm{F}, \mathrm{Cl}, \mathrm{Br}, \mathrm{H})$ dyads is from -7.32 to $-10.89 \mathrm{~kJ} / \mathrm{mol}$ As is clear from Table 3, in the triads, the interaction energies for NCF... $\mathrm{OPH}_{3} \cdots \mathrm{HMgY}, \mathrm{NCCl} \cdots \mathrm{OPH}_{3} \cdots \mathrm{HMgY}$ and $\mathrm{NCBr}$ $\ldots \mathrm{OPH}_{3} \cdots \mathrm{HMgY}$ complexes, span a range from -13.93 to $-17.93 \mathrm{~kJ} / \mathrm{mol}$, from -27.27 to -31.82 $\mathrm{kJ} / \mathrm{mol}$ and from -34.22 to $-39.08 \mathrm{~kJ} / \mathrm{mol}$. According to Table 3, the interaction energies of the halogen bond in the triads, $\mathrm{E}_{\mathrm{i}}(\mathrm{AB}, \mathrm{T})$, are more negative than the respective $E_{i}(A B, D)$ in the dyads. For example,

Table 3. Interaction energies, $\mathrm{E}_{\mathrm{i}}(\mathrm{kJ} / \mathrm{mol})$, and cooperative energies, $\mathrm{E}_{\mathrm{coop}}(\mathrm{kJ} / \mathrm{mol})$, in the investigated dyads (D) and triads $(\mathrm{T})$.

\begin{tabular}{|c|c|c|c|c|c|c|}
\hline Complex $(\mathrm{A} \cdots \mathrm{B} \cdots \mathrm{C})$ & $\mathrm{E}_{\mathrm{i}}(\mathrm{ABC})$ & $\mathrm{E}_{\mathrm{i}}(\mathrm{AB}, \mathrm{D})$ & $\mathrm{E}_{\mathrm{i}}(\mathrm{AB}, \mathrm{T})$ & $\mathrm{E}_{\mathrm{i}}(\mathrm{BC}, \mathrm{D})$ & $\mathrm{E}_{\mathrm{i}}(\mathrm{BC}, \mathrm{T})$ & $\mathrm{E}_{\text {coop }}$ \\
\hline $\mathrm{NCF} \cdots \mathrm{OPH}_{3} \cdots \mathrm{HMgF}$ & -13.93 & -6.20 & -6.61 & -7.32 & -7.74 & -0.41 \\
\hline $\mathrm{NCF} \cdots \mathrm{OPH}_{3} \cdots \mathrm{HMgCl}$ & -14.02 & -6.20 & -6.63 & -7.39 & -7.82 & -0.45 \\
\hline $\mathrm{NCF} \cdots \mathrm{OPH}_{3} \cdots \mathrm{HMgBr}$ & -14.09 & -6.20 & -6.63 & -7.45 & -7.89 & -0.45 \\
\hline $\mathrm{NCF} \cdots \mathrm{OPH}_{3} \cdots \mathrm{HMgH}$ & -17.93 & -6.20 & -7.04 & -10.89 & -11.74 & -0.60 \\
\hline $\mathrm{NCCl} \cdots \mathrm{OPH}_{3} \cdots \mathrm{HMgF}$ & -27.27 & -18.71 & -19.95 & -7.32 & -8.57 & -1.02 \\
\hline $\mathrm{NCCl} \cdots \mathrm{OPH}_{3} \cdots \mathrm{HMgCl}$ & -27.37 & -18.71 & -19.98 & -7.39 & -8.67 & -1.08 \\
\hline $\mathrm{NCCl} \cdots \mathrm{OPH}_{3} \cdots \mathrm{HMgBr}$ & -27.46 & -18.71 & -20.01 & -7.45 & -8.76 & -1.10 \\
\hline $\mathrm{NCCl} \cdots \mathrm{OPH}_{3} \cdots \mathrm{HMgH}$ & -31.82 & -18.71 & -20.93 & -10.89 & -13.11 & -1.57 \\
\hline $\mathrm{NCBr} \cdots \mathrm{OPH}_{3} \cdots \mathrm{HMgF}$ & -34.22 & -25.16 & -26.90 & -7.32 & -9.06 & -1.50 \\
\hline $\mathrm{NCBr} \cdots \mathrm{OPH}_{3} \cdots \mathrm{HMgCl}$ & -34.34 & -25.16 & -26.95 & -7.39 & -9.18 & -1.57 \\
\hline $\mathrm{NCBr} \cdots \mathrm{OPH}_{3} \cdots \mathrm{HMgBr}$ & -34.43 & -25.16 & -26.97 & -7.45 & -9.27 & -1.59 \\
\hline $\mathrm{NCBr} \cdots \mathrm{OPH}_{3} \cdots \mathrm{HMgH}$ & -39.08 & -25.16 & -28.18 & -10.89 & -13.92 & -2.28 \\
\hline
\end{tabular}


$\mathrm{E}_{\mathrm{i}}(\mathrm{AB}, \mathrm{T})$ of the termolecular complexes $\mathrm{NCBr} \cdots$ $\mathrm{OPH}_{3} \cdots \mathrm{HMgH}$ is $-28.18 \mathrm{~kJ} / \mathrm{mol}$, which is more negative than $\operatorname{Ei}(\mathrm{AB}, \mathrm{D})$ of the dyad complexes $\mathrm{NCBr}$.. $\mathrm{OPH}_{3}$ with the value of $-25.16 \mathrm{~kJ} / \mathrm{mol}$. The same trend has been observed, for pnicogen-hydride bond interactions. The pnicogen-hydride bond interactions in the triads are stronger than those in the dyads. For example, the pnicogen-hydride bond interaction energies of $\mathrm{NCBr} \cdots \mathrm{OPH}_{3} \cdots \mathrm{HMgH}$ and $\mathrm{OPH}_{3} \cdots \mathrm{HMgH}$ are -13.92 and $-10.89 \mathrm{~kJ} / \mathrm{mol}$, respectively. Hence, there is positive cooperativity between halogen and pnicogen-hydride bonds in $\mathrm{NCX} \cdot \mathrm{OPH}_{3} \cdots \mathrm{HMgY}$ $(\mathrm{X}=\mathrm{F}, \mathrm{Cl}, \mathrm{Br} ; \mathrm{Y}=\mathrm{F}, \mathrm{Cl}, \mathrm{Br}, \mathrm{H}$ ) complexes. The cooperative energy $\left(\mathrm{E}_{\text {coop }}\right)$ is used to estimate the cooperativity, frequently. It is computed to be the difference between the total interaction energy in the termolecular complexes and the sum of interaction energy in the corresponding bimolecular complexes. ${ }^{14,47}$ The cooperative energy is calculated with the formula of $E_{\text {coop }}=$ $E_{i}(A B C)-E_{i}(A B)-E_{i}(B C)-E_{i}(A C)$. The evaluated cooperativity energy $E_{\text {coop }}$ of the ternary complexes is shown in Table 3. As is shown from Table 3, the $\mathrm{E}_{\text {coop }}$ values are negative in all cases, indicating that there is positive cooperativity between halogen and pnicogenhydride bonds. This cooperative energy is greater than that between the halogen and halogen-hydride bonds. ${ }^{25}$

\subsection{Vibrational analysis}

The amount of calculated frequency shifts of the $\mathrm{C}-\mathrm{X}$ and $\mathrm{O}=\mathrm{P}$ stretching vibrations in the investigated dyads (D) and triads (T) relative to those in the isolated NCX and $\mathrm{OPH}_{3}$ monomers are shown in Table 4. As can be seen, the formation of the complexes leads to a redshift of the $\mathrm{C}-\mathrm{X}$ and $\mathrm{O}=\mathrm{P}$ stretching vibrations in the infrared spectra. The red-shift of the $\mathrm{C}-\mathrm{X}$ and $\mathrm{O}=\mathrm{P}$ stretching vibrations in the triads are larger than those in the dyads. From Table 3 and Table 4, it is seen that the amount of red-shift depends on the strength of the interaction energies The amount of red-shift increases with an increase in the strength of interactions energies. This red shift is smaller than that observed in $\mathrm{OH}$ stretching frequency of the water chain, ${ }^{48}$ which indicates a lower cooperativity between halogen and pnicogen-hydride bonds.

\subsection{Many-body interaction energy analysis}

The two- and three-body contributions to the total interaction energy are calculated by many-body analyses. ${ }^{25,49}$ The non-additive term of the interaction energy or cooperativity has been appraised using the manybody interaction analysis. For this purpose, the two and three-body contributions to total binding energy have been computed. The two-body terms $\left(\Delta \mathrm{E}_{\mathrm{A}-\mathrm{B}}, \Delta \mathrm{E}_{\mathrm{A}-\mathrm{C}}\right.$, and $\Delta \mathrm{E}_{\mathrm{B}-\mathrm{C}}$ ) can be calculated as the difference between the energy of each molecular pair and the energy sum of the monomers, all in the geometry of triad. ${ }^{50}$ The three-body term $\left(\triangle \mathrm{E}_{\mathrm{A}-\mathrm{B}-\mathrm{C}}\right)$ was calculated with the formula of $\Delta \mathrm{E}_{\mathrm{A}-\mathrm{B}-\mathrm{C}}=\mathrm{E}_{\mathrm{i}}(\mathrm{ABC})^{\prime}-\Delta \mathrm{E}_{\mathrm{A}-\mathrm{B}}-\Delta \mathrm{E}_{\mathrm{B}-\mathrm{C}}-$ $\Delta \mathrm{E}_{\mathrm{A}-\mathrm{C}}$, where $\mathrm{E}_{\mathrm{i}}(\mathrm{ABC})$ / was calculated as the difference between the total energy of the optimized triad and the energy sum of the monomers, all in the geometry of triad. Also, the total relaxation energy $\left(E_{R}\right)$ was calculated with the formula of $\mathrm{E}_{\mathrm{R}}=\operatorname{Ei}(\mathrm{ABC})-$ $\Delta \mathrm{E}_{\mathrm{A}-\mathrm{B}}-\Delta \mathrm{E}_{\mathrm{B}-\mathrm{C}}-\Delta \mathrm{E}_{\mathrm{A}-\mathrm{C}}-\Delta \mathrm{E}_{\mathrm{A}-\mathrm{B}-\mathrm{C}}{ }^{51,52}$ The results are listed in Table 5, in which all the energies are corrected for BSSE. The obtained results indicate that for all the complexes, the two- and three-body interaction energies are attractive and they make a positive contribution to the total interaction energy. For the two-body interaction energy in each triad, except the $\mathrm{NCF} \ldots \mathrm{OPH}_{3} \cdots \mathrm{HMgY}(\mathrm{Y}=\mathrm{F}, \mathrm{Cl}, \mathrm{Br}, \mathrm{H})$ complexes, $\Delta \mathrm{E}_{\mathrm{A}-\mathrm{B}}$ is larger than $\Delta \mathrm{E}_{\mathrm{B}-\mathrm{C}}$. Because the distance

Table 4. Frequency shift, $\Delta v\left(\mathrm{~cm}^{-1}\right)$, of $\mathrm{C}-\mathrm{X}$ and $\mathrm{O}=\mathrm{P}$ stretching vibrations in the investigated dyads (D) and triads (T) relative to corresponding monomers.

\begin{tabular}{|c|c|c|c|c|}
\hline Complex $(\mathrm{A} \cdots \mathrm{B} \cdots \mathrm{C})$ & $\Delta v_{\mathrm{C}-\mathrm{X}}(\mathrm{T})$ & $\Delta v_{\mathrm{C}-\mathrm{X}}(\mathrm{D})$ & $\Delta v_{\mathrm{O}=\mathrm{P}}(\mathrm{T})$ & $\Delta v_{\mathrm{O}=\mathrm{P}}(\mathrm{D})$ \\
\hline $\mathrm{NCF} \cdots \mathrm{OPH}_{3} \cdots \mathrm{HMgF}$ & -2.24 & -1.40 & -9.69 & -8.31 \\
\hline $\mathrm{NCF} \cdots \mathrm{OPH}_{3} \cdots \mathrm{HMgCl}$ & -2.01 & -1.40 & -9.65 & -8.33 \\
\hline $\mathrm{NCF} \cdots \mathrm{OPH}_{3} \cdots \mathrm{HMgBr}$ & -2.41 & -1.40 & -9.61 & -8.30 \\
\hline $\mathrm{NCF} \cdots \mathrm{OPH}_{3} \cdots \mathrm{HMgH}$ & -3.65 & -1.40 & -11.17 & -10.45 \\
\hline $\mathrm{NCCl} \cdots \mathrm{OPH}_{3} \cdots \mathrm{HMgF}$ & -9.08 & -8.56 & -11.33 & -8.31 \\
\hline $\mathrm{NCCl} \cdots \mathrm{OPH}_{3} \cdots \mathrm{HMgCl}$ & -9.20 & -8.56 & -11.41 & -8.33 \\
\hline $\mathrm{NCCl} \cdots \mathrm{OPH}_{3} \cdots \mathrm{HMgBr}$ & -9.10 & -8.56 & -11.67 & -8.30 \\
\hline $\mathrm{NCCl} \cdots \mathrm{OPH}_{3} \cdots \mathrm{HMgH}$ & -10.23 & -8.56 & -14.36 & -10.45 \\
\hline $\mathrm{NCBr} \cdots \mathrm{OPH}_{3} \cdots \mathrm{HMgF}$ & -16.56 & -15.68 & -13.86 & -8.31 \\
\hline $\mathrm{NCBr} \cdots \mathrm{OPH}_{3} \cdots \mathrm{HMgCl}$ & -16.76 & -15.68 & -14.11 & -8.33 \\
\hline $\mathrm{NCBr} \cdots \mathrm{OPH}_{3} \cdots \mathrm{HMgBr}$ & -16.98 & -15.68 & -14.32 & -8.30 \\
\hline $\mathrm{NCBr} \cdots \mathrm{OPH}_{3} \cdots \mathrm{HMgH}$ & -19.88 & -15.68 & -16.56 & -10.45 \\
\hline
\end{tabular}


Table 5. Decomposition of interaction energy $(\mathrm{kJ} / \mathrm{mol})$ of the studied ternary complexes.

\begin{tabular}{lrrrrr}
\hline Complex $(\mathrm{A} \cdots \mathrm{B} \cdots \mathrm{C})$ & $\Delta \mathrm{E}_{\mathrm{A}-\mathrm{B}}$ & $\Delta \mathrm{E}_{\mathrm{A}-\mathrm{C}}$ & $\Delta \mathrm{E}_{\mathrm{B}-\mathrm{C}}$ & $\Delta \mathrm{E}_{\mathrm{A}-\mathrm{B}-\mathrm{C}}$ & $\mathrm{E}_{\mathrm{R}}$ \\
\hline $\mathrm{NCF} \cdots \mathrm{OPH}_{3} \cdots \mathrm{HMgF}$ & -6.26 & -0.09 & -7.36 & -0.36 & 0.14 \\
$\mathrm{NCF} \cdots \mathrm{OPH}_{3} \cdots \mathrm{HMgCl}$ & -6.26 & -0.10 & -7.45 & -0.38 & 0.17 \\
$\mathrm{NCF} \cdots \mathrm{OPH}_{3} \cdots \mathrm{HMgBr}$ & -6.26 & -0.10 & -7.51 & -0.38 & 0.17 \\
$\mathrm{NCF} \cdots \mathrm{OPH}_{3} \cdots \mathrm{HMgH}$ & -6.27 & -0.35 & -10.97 & -0.54 & 0.19 \\
$\mathrm{NCCl} \cdot \mathrm{OPH}_{3} \cdots \mathrm{HMgF}$ & -18.82 & -0.26 & -7.34 & -1.09 & 0.24 \\
$\mathrm{NCCl} \cdots \mathrm{OPH}_{3} \cdots \mathrm{HMgCl}$ & -18.83 & -0.27 & -7.42 & -1.12 & 0.26 \\
$\mathrm{NCCl} \cdots \mathrm{OPH}_{3} \cdots \mathrm{HMgBr}$ & -18.82 & -0.27 & -7.50 & -1.12 & 0.25 \\
$\mathrm{NCCl} \cdots \mathrm{OPH}_{3} \cdots \mathrm{HMgH}$ & -18.81 & -0.70 & -10.97 & -1.63 & 0.29 \\
$\mathrm{NCB} \cdots \mathrm{OPH}_{3} \cdots \mathrm{HMgF}$ & -25.40 & -0.34 & -7.32 & -1.56 & 0.41 \\
$\mathrm{NCBr} \cdot \mathrm{OPH}_{3} \cdots \mathrm{HMgCl}$ & -25.40 & -0.35 & -7.42 & -1.60 & 0.44 \\
$\mathrm{NCBr} \cdots \mathrm{OPH}_{3} \cdots \mathrm{HMgBr}$ & -25.39 & -0.36 & -7.49 & -1.62 & 0.43 \\
$\mathrm{NCBr} \cdots \mathrm{OPH}_{3} \cdots \mathrm{HMgH}$ & -25.40 & -0.86 & -10.97 & -2.36 & 0.51 \\
\hline
\end{tabular}

between the interacting molecules $\mathrm{A}$ and $\mathrm{C}$ in all the ternary complexes is the largest, $\Delta \mathrm{E}_{\mathrm{A}-\mathrm{C}}$ of the corresponding triad is the smallest. As is evident, the monomer relaxation energy, $E_{R}$, is slightly small at no more than $0.41 \mathrm{kcal} / \mathrm{mol}$. The relaxation energy is largest in $\mathrm{NCBr} \cdots \mathrm{OPH}_{3} \cdots \mathrm{HMgF}$ and smallest in $\mathrm{NCF} . \mathrm{OPH}_{3} \cdots \mathrm{HMgF}$.

\subsection{NBO analysis}

The natural bond orbital (NBO) method has been used to investigate the nature of $\mathrm{NCX} \cdots \mathrm{OPH}_{3} \cdots \mathrm{HMgY}(\mathrm{X}=$ $\mathrm{F}, \mathrm{Cl}, \mathrm{Br} ; \mathrm{Y}=\mathrm{F}, \mathrm{Cl}, \mathrm{Br}, \mathrm{H}$ ) complexes with coexisting halogen and pnicogen-hydride bonds, which were performed at the MP2/6-311++g(d,p) level of theory based on their geometry optimizations at this level. Table 6 shows the value of charge transfer (CT) from $\mathrm{B}$ to $\mathrm{A}\left(\mathrm{CT}_{\mathrm{AB}}\right)$ and from $\mathrm{C}$ to $\mathrm{B}\left(\mathrm{CT}_{\mathrm{BC}}\right)$ in the triads and its change $(\triangle \mathrm{CT})$ relative to the corresponding dyads. In the $\mathrm{NCF} \cdots \mathrm{OPH}_{3} \cdots \mathrm{HMgY}$ triads, the charge transfer values for the halogen bond are in range of 0.001260.00133 , the values for the pnicogen-hydride bond are in range of $0.00463-0.00672$, and the corresponding values in the ternary $\mathrm{NCCl} \cdots \mathrm{OPH}_{3} \cdots \mathrm{HMgY}$ complexes are between 0.00487-0.00508 and 0.005140.00732 for the halogen and pnicogen-hydride bonds, respectively. Also, in the ternary $\mathrm{NCBr} \cdots \mathrm{OPH}_{3} \ldots$ $\mathrm{HMgY}$ complexes, the amount of charge transfer for the halogen bond is in the range of $0.00798-0.00840$ and for the pnicogen-hydride bond the value is in the range of $0.00145-0.00182$. The charge transfer is largest in ternary complexes associated with bromine halogen bonds. As can be seen from the results, the charge transfer values in the ternary complexes are more than that in the corresponding binary complexes, which indicates amplification of the interactions.

\subsection{AIM analysis}

The atoms in molecules (AIM) methodology has been extensively applied to study the various types of noncovalent interactions. We used the AIM method to analyze the cooperative effects of halogen and pnicogen-hydride bonds. The values of the electron den-

Table 6. Charge transfer, CT (e), in the investigated triads and its changes, $\Delta \mathrm{CT}(\mathrm{e})$, relative to the corresponding dyads.

\begin{tabular}{lcccc}
\hline Complex $(\mathrm{A} \cdots \mathrm{B} \cdots \mathrm{C})$ & $\mathrm{CT}_{\mathrm{AB}}$ & $\Delta \mathrm{CT}_{\mathrm{AB}}$ & $\mathrm{CT}_{\mathrm{BC}}$ & $\Delta \mathrm{CT}_{\mathrm{BC}}$ \\
\hline $\mathrm{NCF} \cdots \mathrm{OPH}_{3} \cdots \mathrm{HMgF}$ & 0.00126 & 0.00019 & 0.00672 & 0.00031 \\
$\mathrm{NCF} \cdots \mathrm{OPH}_{3} \cdots \mathrm{HMgCl}$ & 0.00126 & 0.00019 & 0.00475 & 0.00026 \\
$\mathrm{NCF} \cdots \mathrm{OPH}_{3} \cdots \mathrm{HMgBr}$ & 0.00127 & 0.00020 & 0.00463 & 0.00027 \\
$\mathrm{NCF} \cdots \mathrm{OPH}_{3} \cdots \mathrm{HMgH}$ & 0.00133 & 0.00026 & 0.00637 & 0.00040 \\
$\mathrm{NCCl} \cdot \mathrm{OPH}_{3} \cdots \mathrm{HMgF}$ & 0.00488 & 0.00017 & 0.00732 & 0.00091 \\
$\mathrm{NCCl} \cdots \mathrm{OPH}_{3} \cdots \mathrm{HMgCl}$ & 0.00487 & 0.00016 & 0.00536 & 0.00087 \\
$\mathrm{NCCl} \cdots \mathrm{OPH}_{3} \cdots \mathrm{HMgBr}$ & 0.00487 & 0.00016 & 0.00514 & 0.00078 \\
$\mathrm{NCCl} \cdots \mathrm{OPH}_{3} \cdots \mathrm{HMgH}$ & 0.00508 & 0.00037 & 0.00703 & 0.00106 \\
$\mathrm{NCBr} \cdots \mathrm{OPH}_{3} \cdots \mathrm{HMgF}$ & 0.00799 & 0.00064 & 0.00792 & 0.00151 \\
$\mathrm{NCBr} \cdots \mathrm{OPH}_{3} \cdots \mathrm{HMgCl}$ & 0.00799 & 0.00064 & 0.00597 & 0.00148 \\
$\mathrm{NCBr} \cdots \mathrm{OPH}_{3} \cdots \mathrm{HMgBr}$ & 0.00798 & 0.00063 & 0.00581 & 0.00145 \\
$\mathrm{NCBr} \cdots \mathrm{OPH}_{3} \cdots \mathrm{HMgH}$ & 0.00840 & 0.00105 & 0.00779 & 0.00182 \\
\hline
\end{tabular}


Table 7. Electron densities, $\rho(\mathrm{au})$, at the A $\cdots \mathrm{B}$ and $\mathrm{B} \cdots \mathrm{C}$ intermolecular bond critical points (BCPs) in the investigated triads and its changes, $\Delta \rho$ (au), relative to the corresponding dyads.

\begin{tabular}{|c|c|c|c|c|}
\hline Complex $(\mathrm{A} \cdots \mathrm{B} \cdots \mathrm{C})$ & $\rho_{\mathrm{AB}}$ & $\Delta \rho_{\mathrm{AB}}$ & $\rho_{\mathrm{BC}}$ & $\Delta \rho_{\mathrm{BC}}$ \\
\hline $\mathrm{NCF} \cdot \mathrm{OPH}_{3} \cdots \mathrm{HMgF}$ & 0.00689 & 0.00022 & 0.00557 & 0.00016 \\
\hline $\mathrm{NCF} \cdots \mathrm{OPH}_{3} \cdots \mathrm{HMgCl}$ & 0.00690 & 0.00023 & 0.00561 & 0.00017 \\
\hline $\mathrm{NCF} \cdots \mathrm{OPH}_{3} \cdots \mathrm{HMgBr}$ & 0.00691 & 0.00023 & 0.00564 & 0.00017 \\
\hline $\mathrm{NCF} \cdot \cdots \mathrm{OPH}_{3} \cdots \mathrm{HMgH}$ & 0.00699 & 0.00031 & 0.00624 & 0.00023 \\
\hline $\mathrm{NCCl} \cdots \mathrm{OPH}_{3} \cdots \mathrm{HMgF}$ & 0.01252 & 0.00049 & 0.00592 & 0.00052 \\
\hline $\mathrm{NCCl} \cdots \mathrm{OPH}_{3} \cdots \mathrm{HMgCl}$ & 0.01249 & 0.00046 & 0.00600 & 0.00056 \\
\hline $\mathrm{NCCl} \cdots \mathrm{OPH}_{3} \cdots \mathrm{HMgBr}$ & 0.01251 & 0.00047 & 0.00595 & 0.00048 \\
\hline $\mathrm{NCCl} \cdots \mathrm{OPH}_{3} \cdots \mathrm{HMgH}$ & 0.01279 & 0.00076 & 0.00662 & 0.00061 \\
\hline $\mathrm{NCBr} \cdots \mathrm{OPH}_{3} \cdots \mathrm{HMgF}$ & 0.01511 & 0.00066 & 0.00608 & 0.00068 \\
\hline $\mathrm{NCBr} \cdots \mathrm{OPH}_{3} \cdots \mathrm{HMgCl}$ & 0.01511 & 0.00066 & 0.00611 & 0.00067 \\
\hline $\mathrm{NCBr} \cdot \cdots \mathrm{OPH}_{3} \cdots \mathrm{HMgBr}$ & 0.01511 & 0.00066 & 0.00613 & 0.00067 \\
\hline $\mathrm{NCBr} \cdots \mathrm{OPH}_{3} \cdots \mathrm{HMgH}$ & 0.01546 & 0.00101 & 0.00684 & 0.00084 \\
\hline
\end{tabular}

sity $(\rho)$ at bond critical points (BCPs) located between $\mathrm{A}, \mathrm{B}$ and $\mathrm{C}$ molecules in the triads and its change $(\Delta \rho)$ relative to the corresponding dyads are shown in Table 7. In the ternary complexes, the electron density at the A . . B BCP is in the range of $0.00689-0.01546$ au and at the B ‥ C BCP is in the range of 0.00557-0.00684 au. The results show that the electron density values at the BCPs in all the triads are greater than that in the corresponding dyads, which indicates the strengthening of the interactions. So, comparing the results of the triads and the corresponding dyads may indicate the presence of the cooperative effect.

\section{Conclusions}

MP2/6-311++G(d,p) level calculations were performed to study the interplay between halogen and pnicogen-hydride bonds which coexist in the $\mathrm{NCX} \cdots \mathrm{OPH}_{3} \cdots \mathrm{HMgY}(\mathrm{X}=\mathrm{F}, \mathrm{Cl}, \mathrm{Br} ; \mathrm{Y}=\mathrm{F}, \mathrm{Cl}$, $\mathrm{Br}, \mathrm{H})$ complexes. The $\sigma$-hole was detected on the outer surface of $\mathrm{OPH}_{3}$ molecule. The $\sigma$-hole potential in the $\mathrm{OPH}_{3}$ increases with the presence of halogen bond in $\mathrm{NCX} \ldots \mathrm{OPH}_{3}$ dyads, which means that the complexes are better electron donors than those of the corresponding monomers. Also, the $\mathrm{V}_{\mathrm{S} \text {, min }}$ values outside the oxygen atom become more negative due to the presence of $\mathrm{HMgY}$ in $\mathrm{OPH}_{3} \cdots \mathrm{HMgY}$ complexes. The $\mathrm{R}_{\mathrm{AB}}$ and $\mathrm{R}_{\mathrm{BC}}$ distances in the triads are shorter than those in the dyads. Halogen and pnicogen-hydride bonds in ternary complexes are stronger than in binary complexes. In all cases, halogen bond and pnicogen-hydride bond in triad complexes are stronger than in dyad complexes. There is positive cooperativity between the halogen bond and pnicogen-hydride bond, based on the obtained results. The amount of charge transfer in the triads is greater than those in the corresponding dyads, according to the NBO analysis results. AIM analyses indicate that the halogen bond and pnicogen-hydride bond in the triads are reinforced with respect to the dyads.

\section{Acknowledgements}

The corresponding author is indebted to Dr. A-Reza Nekoei for his encouragement and valuable suggestions. This work was supported by the Young Researchers and Elite Club, Tabriz Branch, Islamic Azad University [grant number 71736] through a research fund. ${ }^{1,41}$

\section{References}

1. Kaplan I G 2006 In Intermolecular Interactions: Physical picture, computational methods and model potentials (Hoboken, New Jersey: John Wiley \& Sons)

2. Vatanparast M and Nekoei A R 2015 Struct. Chem. 26 1039

3. Nekoei A-R and Vatanparast M 2014 New J. Chem. 38 5886

4. Zahedi-Tabrizi M, Tayyari S F, Badalkhani-Khamseh F, Ghomi R and Afshar-Qahremani F 2014 J. Chem. Sci. 126919

5. Kaur D and Kaur R 2015 J. Chem. Sci. 1271299

6. Cavallo G, Metrangolo P, Milani R, Pilati T, Priimagi A, Resnati G and Terraneo G 2016 Chem. Rev. 1162478

7. Jabłoński M and Palusiak M 2012 J. Phys. Chem. A 116 2322

8. Kaur D and Kaur R 2014 J. Chem. Sci. 1261763

9. Chandra S, Iqbal M M and Bhattacharya A $2016 \mathrm{~J}$. Chem. Sci. 1281175

10. Lipkowski P and Grabowski S J 2014 Chem. Phys. Lett. 591113

11. Politzer P, Lane P, Concha M C, Ma Y and Murray J S 2007 J. Mol. Model. 13305

12. Parker A J, Stewart J, Donald K J and Parish C A 2012 J. Am. Chem. Soc. 1345165 
13. Riley K E, Murray J S, Fanfrlìk J, Řezáč J, Solá R J, Concha M C, Ramos F M and Politzer P $2011 \mathrm{~J}$. Mol. Model. 173309

14. Murray J S, Riley K E, Politzer P and Clark T 2010 Aust. J. Chem. 631598

15. Zahn S, Frank R, Hey-Hawkins E and Kirchner B 2011 Chem. - Eur. J. 176034

16. Wei Y, Li Q, Li W, Cheng J and McDowell S A C 2016 Phys. Chem. Chem. Phys. 1811348

17. Del Bene J E, Alkorta I, Sánchez-Sanz G and Elguero J 2013 J. Phys. Chem. A 1173133

18. Scheiner S 2013 CrystEngComm 153119

19. Alkorta I, Elguero J and Del Bene J E 2013 J. Phys. Chem. A 11710497

20. Alkorta I, Sánchez-Sanz G, Elguero J and Del Bene J E 2014 J. Phys. Chem. A 1181527

21. Alkorta I, Elguero J and Solimannejad M 2014 J. Phys. Chem. A 118947

22. Setiawan D, Kraka E and Cremer D 2015 J. Phys. Chem. A 1191642

23. Liu Y-Z, Yuan K, Yuan Z, Zhu Y-C and Zhao X 2015 J. Chem. Sci. 1271729

24. Li Q-Z, Li R, Liu X-F, Li W-Z and Cheng J-B 2012 J. Phys. Chem. A 1162547

25. Vatanparast M 2014 Comput. Theor. Chem. 1048 77

26. Vatanparast M, Taghizadeh M T and Parvini E $2015 \mathrm{~J}$. Theor. Comput. Chem. 141550046

27. Vatanparast M, Parvini E and Bahadori A 2016 Mol. Phys. 1141478

28. Jing B, Li Q, Li R, Gong B, Liu Z, Li W, Cheng J and Sun J 2011 Comput. Theor. Chem. 963417

29. Gong B, Jing B, Li Q, Liu Z, Li W, Cheng J, Zheng Q and Sun J 2010 Theor. Chem. Acc. 127303

30. Li Q-Z, Li R, Liu X-F, Li W-Z and Cheng J-B 2012 ChemPhysChem 131205

31. Del Bene J E, Alkorta I, Sánchez-Sanz G and Elguero J 2012 J. Phys. Chem. A 1169205

32. Esrafili M D, Fatehi P and Solimannejad M 2014 Comput. Theor. Chem. 10341

33. Bader R F W 1990 In Atoms in Molecules: A Quantum Theory (Oxford, UK: Clarendon Press)

34. Reed A E, Curtiss L A and Weinhold F 1988 Chem. Rev. 88899

35. Politzer P, Murray J S and Clark T 2013 Phys. Chem. Chem. Phys. 1511178
36. Frisch M J, Trucks G W, Schlegel H B, Scuseria G E, Robb M A, Cheeseman J R, Montgomery J A, Vreven T, Kudin K N, Burant J C, Millam J M, Iyengar S S, Tomasi J, Barone V, Mennucci B, Cossi M, Scalmani G, Rega N, Petersson G A, Nakatsuji H, Hada M, Ehara M, Toyota K, Fukuda R, Hasegawa J, Ishida M, Nakajima T, Honda Y, Kitao O, Nakai H, Klene M, Li X, Knox J E, Hratchian H P, Cross J B, Bakken V, Adamo C, Jaramillo J, Gomperts R, Stratmann R E, Yazyev O, Austin A J, Cammi R, Pomelli C, Ochterski J W, Ayala P Y, Morokuma K, Voth G A, Salvador P, Dannenberg J J, Zakrzewski V G, Dapprich S, Daniels A D, Strain M C, Farkas O, Malick D K, Rabuck A D, Raghavachari K, Foresman J B, Ortiz J V, Cui Q, Baboul A G, Clifford S, Cioslowski J, Stefanov B B, Liu G, Liashenko A, Piskorz P, Komaromi I, Martin R L, Fox D J, Keith T, Laham A, Peng C Y, Nanayakkara A, Challacombe M, Gill P M W, Johnson B, Chen W, Wong M W, Gonzalez C and Pople J A 2003 Gaussian 03, Revision B.03 (Gaussian, Inc.: Pittsburgh PA)

37. Mohajeri A, Alipour M and Mousaee M 2011 J. Phys. Chem. A 1154457

38. Boys S F and Bernardi F 1970 Mol. Phys. 19553

39. Bulat F, Toro-Labbé A, Brinck T, Murray J and Politzer P 2010 J. Mol. Model. 161679

40. Biegler Konig F W, Schonbohm J and Bayles D $2001 \mathrm{~J}$. Comput. Chem. 22545

41. Glendening E D, Reed A E, Carpenter J E and Weinhold F NBO Version 3.1. (1995)

42. Li W, Zeng Y, Li X, Sun Z and Meng L 2015 J. Comput. Chem. 361349

43. Solimannejad M, Malekani M and Alkorta I $2010 \mathrm{~J}$. Phys. Chem. A 11412106

44. Politzer P and Murray J S 2013 ChemPhysChem 14278

45. Zhou P-P, Qiu W-Y, Liu S and Jin N-Z 2011 Phys. Chem. Chem. Phys. 137408

46. Asiabar B M, Esrafili M D, Mohammadian-Sabet F, Sobhi H R and Javaheri M 2014 J. Mol. Model. 201

47. Wang W and Li Q 2011 Comput. Theor. Chem. 977128

48. Kar T and Scheiner S 2004 J. Phys. Chem. A 1089161

49. Chen W and Gordon M S 1996 J. Phys. Chem. 10014316

50. Solimannejad M, Ramezani V, Trujillo C, Alkorta I, Sánchez-Sanz G and Elguero J 2012 J. Phys. Chem. A 1165199

51. Solimannejad M 2012 ChemPhysChem 133158

52. Hankins D, Moskowitz J W and Stillinger F H $1970 \mathrm{~J}$. Chem. Phys. 534544 